completely deprived of sensibility, while the sub inflammatory pains of paralysed limbs could not be felt if sensibility were lost in them.

Another division of the symptoms of brain disease may prove very useful in practice. I have already alluded to it. Griesinger has published a very interesting paper on this subject. $\mathrm{He}$ insists upon the differences of symptoms belonging to a local affection of the brain in opposition to those due to an affection of the whole brain. In the first class he groups : the cir. cumscribed meningitis (which ends by the production of a collection of matter); the circumscribed encephalitis and its sequences; the local hæmorrhage and tumours. He adds that arterial obliterations, which usually exist in small vessels, generally cause local affections, and thus arises the yellow softening. In the other class of diseases of the brain, in which the symptoms are due to the whole of that organ, he groups the general men ingitis, the diffuse cortical encephalitis, the cerebral anæmia and hyperæmia, the chronic or acute cerebral hypertrophy, the hypertrophy of the cellular tissue of the brain, the atrophy of the hemispheres, the cerebral cedema, and the lesions due to extended affections of bloodvessels. The symptoms of these general diseases of the brain are: vertigo, general cephalalgia, delirium, loss of consciousness, diminution of intelligence going so far as idiocy, coma, trembling or irregular spasms of muscles, general debility, vomiting, and slowness of pulse and of respiration.

Local affections of the brain are generally characterized by the absence of most of the above symptoms and also by the fact that one side of the body is alone affected.

This distinction between symptoms of disease limited to one part of the brain and symptoms of disease of both balves of that organ is certainly an important one; but it must be remembered that an affection limited to a small part of the encephalon may be the cause of a general pressure (effusion, hæmorrhage), and be soon characterized by the very symptoms which belong to diseases of the whole mass of the brain.

I will now say a few words on each of the principal symptoms of brain disease, and on the principal neuroses symptomatic of disease of the brain, and show that they arise from one or several of the nine causes I have already mentioned.*

1. A maurosis. - This symptom may depend upon a lesion of the tubercula quadrigemina, or, of course, of the retina and any part of the length of the optic nerves; but it may also be the result of two other and distinct kinds of causes. It may be due to the effect of an irritation starting from any sensitive nerve in the body, or from certain parts of the nervous centres. An amaurosis in such cases seems to be the manifest result of a reflex action. I have seen it produced in that way in animals after an injury to the spinal cord. I have collected sixty-two cases of disease of the cerebellum in which it has been most likely produced in the same manner. My friend, Dr. Davaine, in his excellent work on Worms, $t$ mentions twelve cases in which amaurosis was due to worms. An irritation of the frontal nerve may bring on a reflex amaurosis, which is quickly cured after the division of the irritated nerve. Neuralgia of the face not rarely causes a reflex amaurosis. I have seen three cases of that kind, and others are on record. $\neq$ It is known that a simple irritation of the nerves of the stomach in gastralgia may produce a reflex amaurosis. This paralysis of the optic nerve, like all other reflex paralyses, is characterized by the following features : 1st, it, of course, only appears after the irritation which is considered as its cause; 2nd, it is not accompanied by any evident alteration of the nerve or of the tubercula quadrigemina; 3rd, it increases or diminishes in perfect correspondence with an increase or a diminution of its supposed cause; 4 th, it is generally quickly cured or ameliorated when the supposed cause is removed.

We need hardly add, that amaurosis may also be induced by an alteration in the quality or quantity of blood. It is so that we find it in cases of lead poisoning, of albuminuria, of diabetes, and of great loss of blood. In those cases it is some. times, but not always, due to an evident organic affection of the retina (such, for instance, as a deposit of albumen). From this short examination of facts relating to amaurosis, it results that this paralysis of the nerve of vision may be produced by either an organic lesion, or by some alteration of nutrition caused by a reflex action, or by a change in the quantity or quality of blood.

* See the preceding number of THE LASCET, p. 2, 2nd column.

+ Traité des Entozoaires et des Maladies Vermineuses. Paris, 1859. pp. $57,109$.

$\ddagger$ See my Course of Lectures on the Central Nerrous System. Lect. 10 .

\section{OBSERVATIONS ON BRONCHOCELE,}

AND

NOTES RELATING TO THE SURGICAL ANATOMY OF THE LARYNX AND TRACHEA.

BY ANDREW M. M'WHINNIE, EsQ, F.R.C.S.

THE thyroid body, in its abnormal hypertrophied state termed Bronchocele or Gottre, undergoes, as is well known, great alteration in form and size, and thereby acquires many new and important relations with the different structures of the neck. Independently of the deformity and inconvenience resulting from its bulk and weight, the swelling may occasion much distress and suffering; it may also, by its interference with the circulation in the large bloodvessels, and by the pressure exerted upon the larynx, trachea, pharynx, and œesophagus, produce even death itself. Amongst the drawings in the pathological collection of St. Bartholomew's Hospital is a representation of a case of this kind-remarkable not so much for its size as for the anatomical relations it had acquired, and which dissection shows would have placed it beyond the reach of surgical interference.

The "Derbyshire neck" is prevalent in certain counties in England, and chiefly amongst females of a strumous diathesis. It is also not uncommon in some districts within a short radius of London. Mr. James Winckworth, of Horsham, Sussex, for instance, tells me that goitre is particularly prevalent about that neighbourhood, and that he has had at the same time as imany as fifteen or sixteen cases in young girls in the Union House. These, he observes, have mostly yielded to medical treatment; and it is fortunate that any severe operative measures directed to the removal of this vascular structuro should be so rarely called for, surrounded as it is by such important parts, and involving during its growth not only the bloodvessels, but also the deep-seated nerves of the neck; indeed, in a long career of practice, whether public or private, the surgeon may seldom meet with a case in which any manual interference beyond that of a puncture is necessary with the view to the diminution of the tumour.

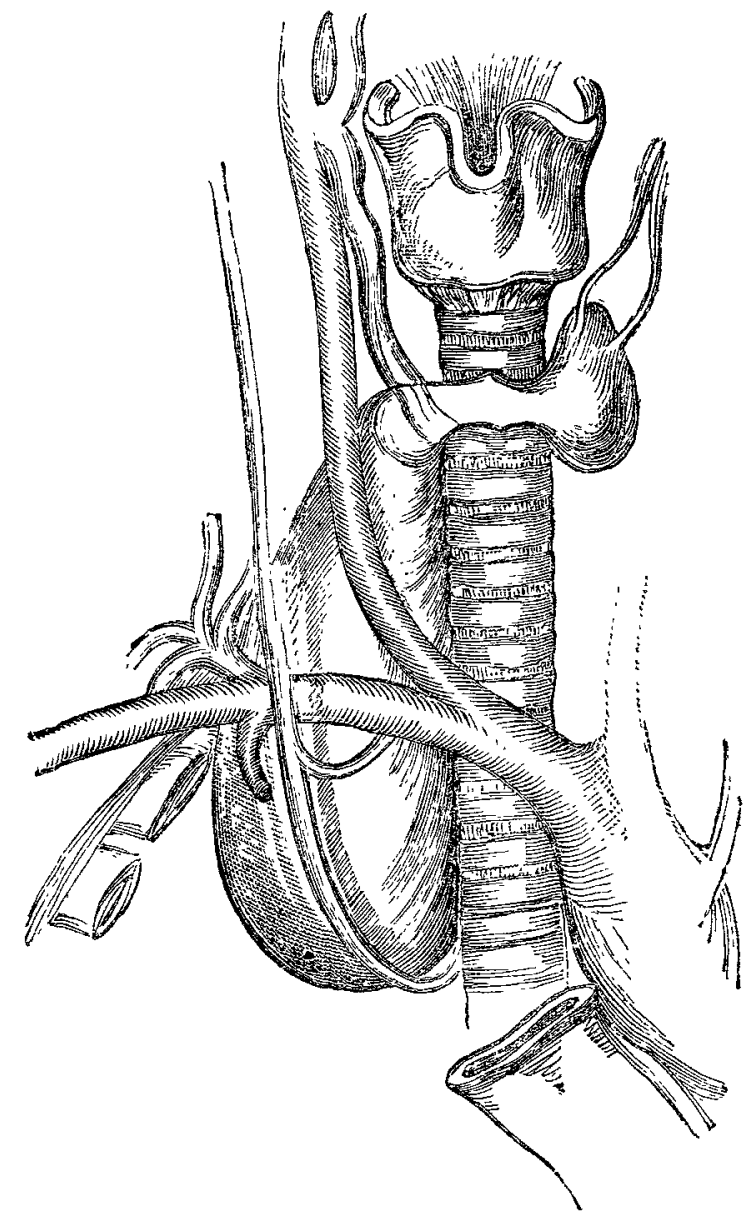


It will be observed in the figure that the left lobe is diminntive, that its cornu does not reach so high as the thyroid cartilage, whilst inferiorly it extends as low only as the fourth, instead of the sixth or seventh, ring of the trachea; but the right lateral lobe had increased so much in dimensions, and particularly in its vertical measurement, that it extended downwards into the chest, nearly as low as the division of the trachea. The shape of this hypertrophied part resembled a large pear, whose apex did not ascend above the level of the isthmus, which last was of the average size. The cornu was deficient. The tumour had insinuated itself internally between the trachea and cesophagus, which it compressed; and externally beneath the common carotid artery and internal jugular vein. The inferior portion of the tumour had the subclavian artery and vein, together with the par vagum, lying in its front, and had pushed down the pleura costalis into the chest, as above mentioned, and had encroached upon the apex of the lung.

The sketch represents the parts as they appeared in an injected female subject, about fifty years old, of whose history nothing was known. Many of the superficial parts of the neck had been dissected away before my attention was directed to the tumour. In respect to its vascular supply, both the superior thyroid arteries were very small, and ramified chiefly on the front surface. In most dissections of bronchocele, I have found the inferior greatly exceed the superior thyroid arteries in size: they may acquire the calibre of the radial, or even of the external carotid arteries.

The thyroid body being frequently nourished so largely by the vessels which dip into its posterior part from below would explain why it undergoes little and sometimes no diminution in bulk, after the operation of tying the superior thyroid arteries.

The right subclavian artery, which is considerably larger than the left, presented a sort of bulbous swelling, and became reduced nearly to half its calibre immediately beyond the thyroid axis. Indeed, we often remarked, in our dissections, that when the thyroid body was enlarged to any extent, no vessel underwent so sudden and marked a diminution in size as the corresponding subclavian, just after the thyroid vessels had branched off from $i$.

When there has been a disparity in the swelling of the two sides, we have mostly found that it was the right side which preponderated in volume. This has been noticed by M. Alibert, and is exemplified by many cases, lately under my own observation, to which I could refer, as well as by all the specimens of the affection preserved in the museum of $\mathrm{St}$. Bartholomew's Hospital, and, with scarcely an exception, in the Hunterian collection. The cysts which we meet with often of large size, and apparently formed by the distended original tissue of the thyroid body, are, I believe, mostly situated in the right lobe. Where, also, have been deposited large masses of calcareous matter, so as to make up a solid tumour, or be sculptured, as it were, into cysts of considerable size, it almost invariably takes place to the greatest extent on the right side.

The tissue throughout the tumour under consideration was coarse and dense, except where there existed small scattered cysts, some with calcareous particles in their walls, and filled with viscid fluid and blood-coloured serum. Upon its surface was deposited some earthy matter at numerous points.

The chief interest connected with this example of bronchocele arises, as has been already noticed, from the remarkable relations which it had acquired during its increase in growth.

My friend, Mr. M`Crea, of Islington, had under his care a youth, aged seventeen, who died from the effects of a large bronchocele, which he had had from infancy. It had caused no inconvenience until he was attacked with bronchitis, from which, however, he recovered a few months before his death. He was found one morning sitting up in bed, labouring under dyspncea, with a livid countenance, and a turgid state of the external jugular veins. He had the appearance of one dying from strangulation. He survived only a few hours afterwards.

On inspection, it was found that the trachea was surrounded by the tumour, which compressed the vessels of the neck. Some particulars of this case are recorded in Dr. Farre's "Journal of Morbid Anatomy." A similar, if not the identical, preparation, exhibiting in a striking manner the en. larged thyroid body, surrounding and compressing the trachea and the lower part of the larynx, is preserved in the museum of St. Bartholomew's Hospital.

Numerous examples may be seen in our museums of the extent to which parts have been encroached upon and thrust aside, altered in position and compressed by this body in its abnormal state, the large vessels surrounded by and buried in the substance of a thick fleshy collar, or a more movable and sometimes pendulous tumour, compressing not only the trachea and bloodvessels, as in the case just cited, but also the larynx, the pharynx, and the osophagus. These could not be reached for the purpose of temporary relief. Starvation, as well as apoplexy and strangulation, might evidently be the consequence of some of these bronchoceles, confined and bound down in some instances by muscles and dense cervical fascia. In the case under notice, the position of the enlarged right lobe is extraordinary, if not unique; for there are not only the arteria innominata and its two large branches lying over the middle, and the pneumogastric, giving off the recurrent, placed on its front surface, but also more than half of the swelling was contained within the cavity of the chest.

It would be difficult to imagine greater obstacles to the surgeon than those here detailed, so deeply does the growth seem to have crept out of reach. Deeply buried and hidden, it contrasts forcibly with the last example of goittre that I have examined,-namely, in a man about fifty years of age, an im. becile patient now under the care of my friend Mr. Stephen Burt. Here is a nodulated pendulons tumour, still from the right lobe of the thyroid body, of about the size of a cocoa-nut, suspended by a narrow neck, and seeming to invite the scalpel. Indeed, with artery forceps in hand, it would not require much boldness to remove it at a level with the integument of the neck, so that little or no perceptible deformity would remain; but this case, so singularly favourable for an operation, is quite exceptional.

The external border of each lateral lobe usually overlaps, more or less, the corresponding carotid artery; but the upper narrower portion which ascends along the trachea and over the side of the larynx may be more deeply situate than that vessel: if, therefore, this part happen to be primarily the seat of enlargement, it is easy to imagine that, with increasing growth, it might make its way behind the large vessels of the neck.

By the enlargement of any one portion of this vascular structinre independently of the others, is explained the endless variety of form that it assumes, and the new and important connexions it acquires, during its growth, with the adjacent parts-embarrassing the diagnosis and rendering surgical operations inadmissible.

When the lateral lobes take a direction backwards, so as to meet sometimes behind the pharynx and cesophagus during their growth, the common carotid arteries are forced outwards over the swelling, where a violent pulsation may be felt and even seen; and apoplectic symptoms may present themselves, arising from venous congestion.

Those amongst us who, in their personal narrative of travel, can be

$$
\begin{aligned}
& \text { "talking of the Alps and Apennines, } \\
& \text { The Pyrenæan and the river Po," }
\end{aligned}
$$

would call to mind, on seeing a large bronchocele, the disfiguring size to which they there attain; and might ask, with Juvenal- "Quis tumidum guttur mixatur in Alpibus ?"

Matthews, in his "Diary of an Invalid," has remarked-_" It would seem as if Nature in these regions could not help break. ing out into excrescence, as well in the animate as in the inanimate part of her creation."

In the valleys amidst the beautiful mountains associated with the heroic deeds of the Swiss in defence of their freedom, exists in the most intense degree cretinism, whose victims are amongst the most pitiable of human beings, and detract so much from the charms of this fair and lovely land; this strange, singular, and no less melancholy combination of goitre with idiocy, imparting that hideous aspect to so many of the inhabitants of the valley of the Alps. "Cent mille hommes dans moins d'un siecle sont frappés dans les vallées des Alpes par cette cruelle maladie," says a writer describing "le Valais et les mours de ses habitans."

It is fortunate that in England it is but little known in those districts in which bronchocele is common, but where cases of cretinism occasionally do occur. Mr. Winckworth informs me that in the district alluded to, bronchocele is often accompanied with idiocy, and that almost all the idiots in the Union-house have enlargement of the thyroid gland.

With regard to the adoption of any surgical means for the relief of this unsightly complaint, we will mention, first, the employment of setons-a practice of very early date, and latterly revived with some advantage, particularly in France and Italy. I saw cases in which they were used with real, at other times with doubtful, benefit at the Hôpital St. Louis, under Baron Alibert. Knowing how admirably setons perform their part in the treatment of still more vascular structures, as 
nævi, also in ranula, bursæ, and cysts in other parts of the body, we might expect that much good might be effected by the introduction of threads by means of fine curved needles through different parts of these swellings; but instances are not wanting of the occurrence of severe inflammation in the parts operated upon, and effects even fatal to life. In the case of a young woman afflicted with bronchocele, Mr. Walters, of Bakewell, Derbyshire, introduced needles, and carried threads through the swelling. This treatment was perfectly successful. "It took it entirely away," he says; " but the inflammation and extreme symptoms that occurred, and which indeed nearly killed her, prevented me ever attempting the same operation again."

(To be continued.)

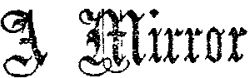

OF THE PRACTICE OF

\section{MEDICINE AND SURGERY IN THE}

\section{HOSPITALS OF LONDON.}

Nulla est alia pro certo noscendi via, nisi quam plurimas et morborum et parare.-Morgagri, De Sed. et Caus. Morb., lib. 14. Procmium.

\section{KING'S COLLEGE HOSPITAL.}

DISARTICULATION OF THE SHOULDER-JOINT FOR A MEDULLARY TUMOUR OF THE UPPER END OF THE HUMERUS ; RECOVERY.

(Under the care of Mr. FERGJSSON.)

THE removal of the arm at the shoulder-joint is never performed except for severe and dangerous injury to the upper part of the limb, or for extensive disease of the humerus of a malignant character. The greater number of cases in which this important measure has been resorted to have been gun-shot injuries. In the "Dictionary of Surgery," Mr. Samuel Cooper refers to upwards of a hundred cases amputated at the shoulder by Baron Larrey and his colleagues, more than ninety of which recovered. In Larrey's acconnt of his campaign in Egypt, of nineteen patients thus operated upon, thirteen recovered.

If the statistics of the removal of the arm at the shoulderjoint could be collected, there can be no doubt that the success would be found nearly as great in civil as in military practice. The form of injury requiring it in our hospitals is usually crushing of the limb by machinery, which sometimes involves the joint. Of the four cases which we now record, in two disarticulation became necessary in consequence of the severity of the lesions inflicted: in one, the greater part of the arm was torn off, nevertheless a good recovery ensued; in the other, several ribs were broken, the pleura lacerated, the arm and forearm broken, and the soft structures much torn, which caused a fatal result.

The other cases were examples of malignant disease affecting the shaft of the humerus, which left no alternative but that adopted. In Mr. Fergusson's patient a large tumour involved the bone close to its head, which, of course, modified the operation, and wholly precluded its performance by transfixion. The remarks of Mr. Samuel Cooper on this point are here most apposite:- " That no mode of amputating at the shoulder can be exclusively employed in all the cases requiring the operation, because the soft parts around the joint are frequently destroyed, or very much injured to a greater or lesser extent, so that the surgeon is obliged to save skin and muscles wherever he can find them." (Surgical Dictionary, p. 86.)

In the following case the deltoid and scapular muscles were attenuated and spread out over the tumour. The employment of an ordinary long-bladed bistoury, therefore, was sufficient to effect the disarticulation, which was accomplished with much celerity, under the influence of chloroform, and with the loss of comparatively but little blogd. The disease proved to be malignant, as was suspected, developed within the shaft, quite close to the head, and having a thin shell of expanded bone around it, perforated in one or two places by the disease, We are happy to state that a very good recovery has taken place, although the patient is still in hos. pital.

For the notes of the case we are indebted to Mr. G. Fortescue, house-surgeon to the hospital:-

Anne $\mathrm{H}-$, aged twenty-eight, married, the mother of three children, a native of Shrivenham, Berkshire, tolerably stout and well-nourished, but of sallow and somewhat anæmic complexion, which, however, she says, has always been natural to her, was admitted June 18th, 1861. About eighteen months ago she first experienced some pain and difficulty of movement in the right shoulder-joint, attributable, as was supposed, to over-exertion in lifting a heavy weight some months previously. The pain, dull, deep-seated, aching, and worse generaliy at night, continued to increase, until, in A pril, 1860, some fulness of the limb below the joint was observed, and she became a patient at the Reading Hospital, where counter-irritants were employed, with the result of lessening the pain, but with no effect in retarding the progress of the swelling, in proportion to the increase of which the pain appeared to diminish. In July, 1860, and the ensuing three or four months, the growth of the tumour was very rapid, since which time, though slowly increasing, it has remained comparatively stationary. In October last she first saw Mr. Fergusson. She was then nursing a child of three months old, and was so feeble and anæmic that any operative interference was thought to be at that time inadmissible.

On admission, there was a large, firm, and moderately regular tumour at the upper end of the right humerus, involving the upper third of the bone, and moving freely with it, sinking gradually into the shaft below, above much expanded, especially towards the outer side, around the articulating surface, limiting very considerably the movements of the joint, which, however, within those limits, were tolerably free and painless; firm, in parts very hard, to the touch; softer and a little irregular in front; the skin unadherent; the superficial veins above and in front enlarged and tortuous; the axillary glands not implicated. No family history of malignant disease. She was ordered a liberal diet, and ten minims of tincture of the sesquichloride of iron, and two grains of quinine, in infusion of calumba, thrice a day.

On Saturday, June 15th, the patient having been put undex the influence of chloroform, Mr. Fergusson removed the arm at the shoulder-joint. A semilunar incision was made with a stout bistoury into the skin and subcutaneous tissues at the outer and back part of the limb, at the level of the insertion of the deltoid, the flap dissected up, the cavity of the joint opened, the bone turned out, and the separation completed by the division of the tissues at the inner side of the arm. From the main artery, which was compressed above the clavicle, and seized at once between the finger and thumb when cut through, little or no hæmorrhage occurred; it was rather free, however, from numerous smaller vessels. No trace of disease remained in the flaps, and the glenoid cavity was unaffected.

June 25th. -The patient, now nearly convalescent, has pro gressed, almost without a bad symptom, since the operation. Symptomatic fever ran rather high for the first four or five days. The discharge, at first extremely copious, thin, and very offensive, consisting in great part of disintegrating blood clots, to allow of the escape of which most of the stitches were early removed, is now small in amount and healthy. The ligatures, except the one on the main vessel, have come away. The wound, now dressed with a stimulating lotion, looks most healthy, and is united in a considerable part of its extent. She takes solid food well, is without pain, and gets stronger daily.

July 8th. - She is now sitting up, the stump has nearly healed, and she is doing as well as could be wished.

The tumour on removal was found to measure more than thirteen inches in circumference. The deltoid and scapular muscles were thinned and spread out over it. It consisted chiefly of a mass of soft, medullary-like substance, bounded externally by a very thin layer of the expanded bone, except in one or two places, through which the neighbouring tissues had been partially invaded. The articulating surface, perfectly smooth and natural, appeared set in the upper poition of the expansion.

\section{WESTMINSTER HOSPITAL.}

DISARTICULATION OF THE SHOULDER-JOINT FOR A RECURRENT FIBROID TUMOUR OF THE ARM ; RECOVERY.

(Under the care of Mr. HoLT.)

THE subject of the following case underwent two previons operations before her admission into the above hospital, and 